\title{
The Impact of Slow-Stroke Back Massage on Anxiety Among Patients Receiving Hemodialysis: A Randomized Clinical Trial
}

\author{
Mina Nahamin, ${ }^{1}$ Masumeh Akbarbegloo, ${ }^{2,}$ and Zeinab Habibipur ${ }^{2}$ \\ ${ }^{1}$ Student Research Committee, Tabriz University of Medical Sciences, Tabriz, IR Iran \\ ${ }^{2}$ Department of Nursing, Faculty of Khoy Nursing and Health Sciences, Urmia University of Medical Sciences, Urmia, Iran \\ "Corresponding author: Masumeh Akbarbegloo, Department of Nursing, Faculty of Khoy Nursing and Health Sciences, Urmia University of Medical Sciences, Urmia, IR Iran. \\ Tel: +98-4436255777, Fax: +98-4436255777, E-mail: m.akbarbegloo@yahoo.com
}

Received 2016 March 01; Accepted 2016 April 15.

\begin{abstract}
Background and Aim: Anxiety is among the commonest psychological problems experienced by patients receiving hemodialysis. One of the anxiety management strategies is complementary therapy. The aim of the present study was to investigate the effects of slow-stroke back massage on anxiety among hemodialysis patients.

Methods: This randomized controlled clinical trial was carried out in a sample of 60 patients. The patients were allocated either to an experimental or a control group through simple random allocation. Patients in the experimental group received a slow-stroke back massage for 10 minutes thrice a week during 4 consecutive weeks, while patients in the control group received routine care services and had no information about the intervention provided to the patients in the experimental group. The level of anxiety was measured using Splielberger's State-trait anxiety inventory at 3 time points, namely, after hemodialysis and before the intervention, 15 days after the intervention, and 30 days after the intervention. Data were entered into SPSS software (v. 16.0) and analyzed through running the repeated measures analysis of variance and the independent-sample t-test. Descriptive statistic measures were used for data description.

Results: The repeated measures analysis of variance showed that slow-stroke back massage significantly alleviated state and trait anxiety at 15 and 30 days after the intervention $(\mathrm{P}<0.001)$. Thirty days after the intervention, the means of state anxiety in the experimental and control groups were $34.7 \pm 7.4$ and $46.2 \pm 7.3$ while the means of trait anxiety were $35.2 \pm 8.4$ and $46.2 \pm 7.4$, respectively. The means of the pretest-posttest mean difference of state anxiety on the 15th and 30th day after the intervention in the experimental group were $10.6 \pm 8.5$ and $12.8 \pm 7.2$ while the means of the trait anxiety pretest-posttest mean difference were 7.7 \pm 8.2 and $10.7 \pm 3.4$, respectively. The means of posttest state and trait anxiety in the experimental group were significantly lower than the baseline values $(\mathrm{P}<0.001)$.
\end{abstract}

Conclusions: Using massage therapy programs can positively affect the level of anxiety among patients receiving hemodialysis.

Keywords: Slow-Stroke Back Massage, Anxiety, Hemodialysis

\section{Introduction}

Chronic renal failure (CRF) is a progressive irreversible renal disorder in which the body loses its ability to sustain fluid and electrolyte balance and thus, the afflicted individual develops azotemia and uremia (1). Currently, there are more than 200,000 patients suffering from CRF in the United States, with a total of around 1 million patients worldwide (2). According to the statistics released by the Iranian Foundation for Special Diseases, the number of Iranian patients with CRF in 2001 was 16,467, from which $52 \%$ were treated with hemodialysis, $47 \%$ with kidney transplantation, and $1 \%$ with peritoneal dialysis. In other words, the prevalence of CRF in Iran is 253 cases per a population of 1 million. This amount is far lower than the prevalence rate of CRF in developed countries (i.e. 476-1150 cases per a population of 1 million), which is probably due to the inadequate treatment and early death of patients with CRF in Iran $(3,4)$. The number of Iranian patients receiving hemodialysis increases by $15 \%$ each year (4).

Anxiety is one of the most common psychological problems experienced by patients receiving hemodialysis. Lengthy treatments and an inadequate support system undermine the patients' ability to cope with stressful situations and could thus result in different levels of anxiety (5). Anxiety is a diffuse unpleasant vague feeling which is associated with worry and a sense of imminent danger. It can be associated with a series of physiological symptoms such as palpation, headache, sweating, dyspnea, and restlessness, which increase the body's metabolic rate, lower immunity, and aggravate the symptoms of the underlying illnesses, particularly among patients with chronic conditions such as CRF. In addition, untreated anxiety can lead to depression, a reduce quality of life, and undermine satisfaction with treatment and healthcare providers (6).

Patients undergoing hemodialysis experience differ- 
ent physiological problems such as fatigue, decreased mobility, hypotension, muscle spasm, nausea and vomiting, inadequate food and fluid intake, and a disturbed daily life (7). Other problems experienced by this patient population include, but not limited to, daily stress, preoccupation with CRF and its consequences, limited physical activity, impaired social functionality, dependence on healthcare providers, limited familial and sexual functions, long periods of time for receiving lengthy hemodialysis, and occupational and financial problems (8).

Stasiak et al. (2014) reported that all hemodialysis patients experienced some levels of anxiety, while most of them (58.9\%) suffered from moderate anxiety (5). Cukor et al. (2008) also found that the prevalence of anxiety disorders among patients with CRF is twice as high than the national average in the United States (9). Anxiety can cause frequent hospitalizations and an increase in morbidity, healthcare costs, and mortality rate in patients undergoing hemodialysis (5). One of the strategies for anxiety management is medication therapy. However, prescription of medication is not among the responsibilities of nurses. Moreover, medication can cause different side effects and put patients at added health risks. Thus, adopting safer anxiety management strategies seems essential (10). One of the safest and most cost-effective strategies for anxiety management is complementary therapy, the use of which is progressively increasing in healthcare centers (11). The British Medical Association estimated that 180 kinds of complementary therapies were used in the United Kingdom in 1993. These therapies include music therapy, guided imagery, praying, touch therapy, hypnosis, acupuncture, yoga, homeopathy, massage and so on (12).

The word "massage" comes from the Greek word "massein" and the Latin word "manus" which mean "to rub" and "hand", respectively. Massage includes a series of manual procedures that are systematically performed on body tissues in order to affect the nervous, musculoskeletal, integumentary, and circulatory systems. There are different types of massage therapy. One approach to massage therapy is slow-stroke back massage (SSBM), during which the back is massaged through slow rhythmic movements by the therapist's hands at a steady rate of 60 movements per minute $(13,14)$.

Previous studies show that SSBM is an effective nursing procedure for relaxing patients and alleviating their anxiety, fatigue, and pain. For example, Yeganekhah (2006) reported that SSBM had potential effects on anxiety and its complications among residents of the Kahrizak nursing home in Tehran, Iran (15). Bazrafshan and Ghorbani (2010) also found SSBM to be effective in alleviating anxiety among primigravida women living in Tehran, Iran (16).

Given the increasing number of hemodialysis pa- tients and the high prevalence of fatigue and anxiety among them, employing strategies to alleviate their anxiety clearly seems essential (6). The results of a metaanalysis on all studies conducted from 1991 to 2009 in the area of SSBM showed that it had positive physiological and psychological effects on elderly people. However, its effects on anxiety among hemodialysis patients have not yet been investigated. Therefore, the present study was carried out to fill this gap. The aim of the study was to investigate the effects of SSBM on anxiety among hemodialysis patients.

\section{Methods}

This single-blind randomized controlled clinical trial was carried out in the Boali teaching hospital in Ardabil, Iran. The sample size was determined to be 30 patients for each study group based on the formula for comparing two means, the results of a previous study (17), a confidence interval of $95 \%$, and a power of $80 \%$. Sampling was performed conveniently while allocation of patients to groups was performed randomly by using the simple random allocation. The eligibility criteria were receiving hemodialysis 3 times a week for at least 3 consecutive months, experiencing no stressful life events during the past 6 months before the study, using no tranquilizer or anxiety-management modality (such as physical exercise) during the past 6 weeks before the study, having no drug addiction, having no wound, erythema, or abnormal swelling over the back, and obtaining a state and a trait anxiety score of less than 63 and 64, respectively.

Patients in the experimental group were treated with SSBM during 4 weeks. Accordingly, a massage therapist (the first author) massaged each female patient's back for 10 minutes thrice a week through gentle and rhythmic hand movements at a steady rate of 60 movements a minute. Male patients received SSBM from a male research assistant who had received necessary SSBM-related training. SSBM was provided to the patients in the afternoons between 15:00 and 17:00 in a quiet private room located at the dialysis unit of the study setting. Patients in the control group received routine care services and had no information about the SSBM intervention provided to the patients in the experimental group. The steps of SSBM were as follows,

1) Placing the patient in the prone position on a hard bed;

2) Performing narrow-range rotational thumb movements over the neck;

3) Performing superficial stroke movements over one side of the spine from the base of the skull to the sacral area using the plantar surface of one hand while the other hand was moved from the sacral area to the base of the skill; 
4) Performing stroke movements over the shoulder using the thumbs;

5) Performing stroke movements over both sides of the spine from the shoulder to the waist using the thumbs;

6) Performing sweeping stroke from the neck towards the sacral area using the plantar surfaces of both hands.

The data collection tool was a demographic questionnaire and Spielberger's State-train anxiety inventory (STAI). The STAI consists of the state and the trait anxiety subscales which measure manifest and latent anxiety, respectively. State anxiety can be considered as a section of life. In other words, it is situational and happens in stressful situations (such as debates, loss of a social status, security or health threats, etc.), while trait anxiety deals with individual differences in response to stressful situations with different levels of state anxiety. Each of the STAI subscales contains 20 items. The items of the state anxiety subscale are scored on a four-point Likert-type response scale from 1 to 4 , which stand for "Not at all" to "Very much", respectively. On the other hand, respondents should respond to the items of the trait anxiety subscale based on their own usual and dominant feelings by using a four-point Likerttype response scale from 1 ("Almost never") to 4 ("Almost always"). Scores 1 and 4 in ten items of the state anxiety subscale and eleven items of the trait anxiety subscale represent the lowest and the highest levels of anxiety, respectively. However, in the remaining ten items of the state anxiety subscale and nine items of the trait anxiety subscale, scores 1 and 4 represent the highest and the lowest levels of anxiety, respectively. In other words, items, which represent lack of anxiety, are scored reversely. The total score of each subscale ranges from 20 to 80 (18). A research assistant measured the level of anxiety among the participants at 3 time points, namely, after hemodialysis and before the intervention (T1), 15 days after the intervention(T2), and 30 days after the intervention (T3).

This study gained the approval of the institutional review board and the ethics committee of Tabriz University of Medical Sciences in Tabriz, Iran, and was registered in the Iranian registry of clinical trials with the code IRCT201211046801N2. All patients signed the informed consent form and were ensured about the confidentiality of their personal data and the voluntary basis of participation in the study. Data collection was started and performed after making necessary adjustments with the headnurse, the prescribing physicians, and the administrators of the study setting. The aim of the study was also described to the participants.

The data were analyzed using SPSS software (v. 16.0). Descriptive statistic measures were used for data description while the repeated measures analysis of variance (RM ANOVA) and the independent-sample t-test were used for data analysis. The level of significance was less than 0.05 .

\section{Results}

Out of the 60 patients who participated in the study, 31 (51.66\%) were male and 29 (48.33\%) were female. The mean of participants' age was $48.8 \pm 12.5$. Age means in the experimental and the control groups were $49.46 \pm 2.17$ and $50.73 \pm 1.90$. There were no statistically significant differences between the groups regarding the participants' demographic characteristics ( $\mathrm{P}>0.05)$.

The mean dialysis time among all participants was $48.35 \pm 25.79$ months while this value in the experimental and the control groups was $42.46 \pm 20.48$ and $48.23 \pm 21.28$ months, respectively. Around $60 \%$ of patients in the control group and 50\% of patients in the experimental group received hemodialysis 3 times a week. Moreover, in the experimental and the control groups, respectively $30.8 \%$ and $40 \%$ of patients were maximally dialyzed for 2 hours per session. The results of the statistical tests illustrated no significant difference between the groups with respect to dialysis time, number of dialysis sessions in a week, and length of each dialysis session $(\mathrm{P}>0.05)$.

The means of baseline state anxiety in the experimental and the control groups were $47.4 \pm 8.7$ and $48.4 \pm 8.1$, respectively. These values for trait anxiety were $45.5 \pm 9.1$ and $47.4 \pm 8.1$, respectively. Thirty days after the intervention, the means of state anxiety in the groups were $34.7 \pm$ 7.4 and $46.2 \pm 7.3$ while the means of trait anxiety were 35.2 \pm 8.4 and $46.2 \pm 7.4$, respectively. The RM ANOVA showed that in the experimental group, the levels of state and trait anxiety at $\mathrm{T} 2$ and $\mathrm{T} 3$ were significantly lower than the baseline anxiety levels $(\mathrm{P}<0.001)$ while in the control group, the difference between the measurement time points was not statistically significant $(\mathrm{P}>0.05$; Tables 1 and 2$)$. The results of the independent-sample t-test also illustrated significant between-group differences regarding the levels of state and trait anxiety at $\mathrm{T} 2$ and $\mathrm{T} 3$.

\section{Discussion}

This study aimed at investigating the effects of SSBM on anxiety among hemodialysis patients. The results revealed SSBM to be effective in significantly alleviating state and trait anxiety $(\mathrm{P}<0.001)$

In line with our findings, Holland and Pokorny (2001) found that 3-minute SSBM for 3 consecutive days significantly reduced the means of blood pressure, heart rate, and anxiety among elderly people and improved nurseclient relationships (19). Besides, Yeganekhah (2006) set up a quasi-experimental study to investigate the effects of 
Table 1. State Anxiety Scores in Both Groups ${ }^{a}$

\begin{tabular}{lccc}
\hline Time & $\begin{array}{c}\text { Experimental } \\
\text { Group }\end{array}$ & Control Group & $\begin{array}{c}\text { The Results of } \\
\text { the } \\
\text { Independent- } \\
\text { Sample } \\
\text { T-Test }\end{array}$ \\
\hline Before(T1) & $47.4 \pm 8.7$ & $48.4 \pm 8.1$ & $\begin{array}{c}\mathrm{t}=0.324, \mathrm{df}= \\
58, \mathrm{P}=0.567\end{array}$ \\
$\begin{array}{l}\text { After 15 days } \\
\text { (T2) }\end{array}$ & $36.6 \pm 6.2$ & $47.3 \pm 7.2$ & $\begin{array}{c}\mathrm{t}=-1.745, \mathrm{df}=58, \\
\mathrm{P}=0.024\end{array}$ \\
$\begin{array}{l}\text { After 30 days } \\
\text { (T3) }\end{array}$ & $34.7 \pm 7.4$ & $46.2 \pm 7.3$ & $\begin{array}{c}\mathrm{t}=-3.308, \mathrm{df}= \\
58, \mathrm{P}=0.012\end{array}$ \\
The RM ANOVA & $\mathrm{F}=24.1, \mathrm{df}=2, \mathrm{P}$ & $\mathrm{F}=3.1, \mathrm{df}=2, \mathrm{P}<$ & \\
\hline & $<0.001$ & 0.112 & \\
\hline
\end{tabular}

${ }^{\mathrm{a}}$ Values are expressed as mean $\pm \mathrm{SD}$.

Table 2. Trait Anxiety Scores in Both Groups

\begin{tabular}{lccc}
\hline Time & $\begin{array}{c}\text { Experimental } \\
\text { Group }\end{array}$ & Control Group & $\begin{array}{c}\text { The } \\
\text { Independent- } \\
\text { Sample } \\
\text { T-Test }\end{array}$ \\
\hline Before (T1) & $45.5 \pm 9.1$ & $47.4 \pm 8.1$ & $\begin{array}{c}\mathrm{t}=0.432, \mathrm{df}= \\
58, \mathrm{P}=0.667\end{array}$ \\
$\begin{array}{l}\text { After 15 days } \\
\text { (T2) }\end{array}$ & $37.7 \pm 8.7$ & $46.7 \pm 6.5$ & $\begin{array}{c}\mathrm{t}=-1.598, \mathrm{df}= \\
58, \mathrm{P}=0.031\end{array}$ \\
$\begin{array}{l}\text { After 30 days } \\
\text { (T3) }\end{array}$ & $35.2 \pm 8.4$ & $46.2 \pm 7.4$ & $\mathrm{t}=-3.652, \mathrm{df}=$ \\
& & $58, \mathrm{P}=0.019$ \\
The RM ANOVA & $\mathrm{F}=21.8, \mathrm{df}=2, \mathrm{P}$ & $\mathrm{F}=1.61, \mathrm{df}=2, \mathrm{P}$ & \\
\hline & $<0.001$ & $<0.214$ & \\
\hline
\end{tabular}

SSBM on anxiety and hypertension among elderly people and found SSBM to be effective in significantly alleviating anxiety (15).

Bazrafshan and Ghorbani (2010) also assessed the effects of SSBM on anxiety among primigravida women and found that SSBM significantly alleviated anxiety (16). The results of a study by Goodfellow (2003) on 42 cancer patients also illustrated that a 20-minute SSBM significantly relieved anxiety (20). Taylor et al. (2003) also found Swedish massage effective in significantly alleviating postoperative anxiety (21). Moreover, Mokhtari-Noori et al. (2009) reported the positive effects of foot reflexology and Benson's relaxation on anxiety among patients undergoing abdominal surgeries (22). Torabi et al. (2012) also found that foot reflexology and Benson's relaxation had positive effects on anxiety and physiological parameters among candidates for coronary angiography (23) as well as on anxiety among candidates for kidney transplantation (17). Additionally, Adib-Hajbaghery et al. (2012) found that massage relaxed muscles, brought about tranquility, reduced fatigue and pain, created a sense of sleepiness, and alleviated anxiety (24).
The findings of the present study also illustrate significant between-group differences regarding state and trait anxiety at T2 and T3 $(\mathrm{P}<0.05)$. Moreover, there were significant differences between $\mathrm{T} 2$ and $\mathrm{T} 3$ with respect to the levels of state and trait anxiety ( $\mathrm{P}<0.05$; Tables 1 and 2). Bauer et al. (2010) also assessed the effects of massage therapy on candidates for cardiac surgery and found that the level of anxiety significantly increased 24 hours after their intervention but significantly decreased at days 2 and 4 after their intervention (25). Repetitions of massage therapy and increases in the length of massage therapy sessions might have resulted in a gradual decrease in the level of anxiety in Bauer and colleagues' study.

Contrary to our findings, Billhult et al. (2007) reported that 20 minute massage therapy for 5 times during 3 - 4 weeks had no significant effect on anxiety among cancer patients receiving chemotherapy (26). The type of the underlying conditions (benign or malignant) in these 2 studies might have contributed to such conflicting findings. Besides, other stressors such as an uncertain future and inability to perform familial and social roles can affect the level of anxiety among cancer patients. Maryami et al. (2003) also implemented a massage therapy intervention (3 sessions on 3 consecutive days) for women who were candidates for hysterectomy. They measured the level of the women's state anxiety both before and after each massage therapy session. Before their intervention, there was no significant difference between their experimental and control groups regarding the state anxiety. However, the variations of the mean differences of pre- and post-massage anxiety across the 3 measurement time points were statistically significant in the experimental group. Moreover, the level of state anxiety in their experimental group was statistically lower than their control group even 5 days after their intervention (27).

One of the limitations of the present study was the inability to control the intervening effects of environmental factors (such as noises) on the general atmosphere of the massage therapy room. Besides, individual differences among the participants (such as their mental status and personality characteristics) might have affected the findings.

\subsection{Conclusions}

The findings of the present study suggest that SSBM alleviates both state and trait anxiety and improves mental status among patients receiving hemodialysis. Given the adverse effects of anxiety and anxiolytic medication, SSBM can be used as a simple, safe, inexpensive, and noninvasive procedure to alleviate anxiety and reduce the use of chemical tranquilizers. Health policy makers, hospital designers, and other healthcare providers could use the 
findings of the present study to promote the use of nonpharmacological therapies.

\section{Acknowledgments}

This article was derived from a thesis approved by Tabriz University of Medical Sciences in Tabriz, Iran. The authors would like to show their sincere gratitude to the administrators, staff, and patients of the hemodialysis unit of Boali hospital in Ardabil, Iran.

\section{References}

1. Sutters M, Kelly M. Special care, a unique and intensive dialysis service. Commu Connect. 2013;2(3):2-5.

2. Potter PA, Perry AG, Stockert P, Hall A. Fundamentals of nursing. Elsevier Health Sciences; 2016.

3. Ahmad MM, Al Nazly EK. Hemodialysis: stressors and coping strategies. Psychol Health Med. 2015;20(4):477-87. doi: 10.1080/13548506.2014.952239. [PubMed: 25158058].

4. Abreo AP, Glidden D, Painter P, Lea J, Herzog CA, Kutner NG, et al. Association of physical function with predialysis blood pressure in patients on hemodialysis. BMC Nephrol. 2014;15:177. doi: 10.1186/14712369-15-177. [PubMed: 25399253].

5. Stasiak CE, Bazan KS, Kuss RS, Schuinski AF, Baroni G. Prevalence of anxiety and depression and its comorbidities in patients with chronic kidney disease on hemodialysis and peritoneal dialysis. JBras Nefrol. 2014;36(3):325-31. [PubMed: 25317615].

6. Dziubek W, Kowalska J, Kusztal M, Rogowski L, Golebiowski T, Nikifur M, et al. The Level of Anxiety and Depression in Dialysis Patients Undertaking Regular Physical Exercise Training-a Preliminary Study. Kidney Blood Press Res. 2016;41(1):86-98. doi:10.1159/000368548. [PubMed: 26872253].

7. Kaze FF, Ashuntantang G, Kengne AP, Hassan A, Halle MP, Muna W. Acute hemodialysis complications in end-stage renal disease patients: the burden and implications for the under-resourced SubSaharan African health systems. Hemodial Int. 2012;16(4):526-31. doi 10.1111/j.1542-4758.2012.00692.x. [PubMed: 22541071].

8. Hatthakit U. Lived experiences of patients on hemodialysis: a metasynthesis. Nephrol Nurs J. 2012;39(4):295-304. [PubMed: 23061114] quiz 305.

9. Cukor D, Coplan J, Brown C, Friedman S, Newville H, Safier M, et al. Anxiety disorders in adults treated by hemodialysis: a single-center study. Am J Kidney Dis. 2008;52(1):128-36. doi: 10.1053/j.ajkd.2008.02.300. [PubMed: 18440682].

10. Imanishi J, Kuriyama H, Shigemori I, Watanabe S, Aihara Y, Kita M, et al. Anxiolytic effect of aromatherapy massage in patients with breast cancer. Evid Based Complement Alternat Med. 2009;6(1):123-8. doi: 10.1093/ecam/nem073. [PubMed: 18955225].

11. Maddocks-Jennings W, Wilkinson JM. Aromatherapy practice in nursing: literature review. J Adv Nurs. 2004;48(1):93-103. doi: 10.1111/j.13652648.2004.03172.x. [PubMed: 15347415].
12. Woodrow P. Intensive care nursing: a framework for practice. Routledge; 2002

13. MokE, Woo CP. The effects of slow-stroke back massage on anxiety and shoulder pain in elderly stroke patients. Complement Ther Nurs Midwifery. 2004;10(4):209-16. doi: 10.1016/j.ctnm.2004.05.006. [PubMed: 15519938].

14. Harris M, Richards KC, Grando VT. The effects of slow-stroke back massage on minutes of nighttime sleep in persons with dementia and sleep disturbances in the nursing home: a pilot study. J Holist Nurs. 2012;30(4):255-63. doi: 10.1177/0898010112455948. [PubMed: 23007716].

15. Yeganekhah M. Effect of SSBM on anxiety and hypertension elderly resident Kahrizak. Welfare and Rehabilitation University; 2006.

16. Bazrafshan M, Ghorbani Z. Effect of massage stroke technique on anxiety level back primigravid women. Hayat. 2010;16(1):34-40.

17. Torabi M, Salavati M, Pourismail Z, Akbarzade Baghban A. The Effects of Acupressure and Benson Relaxation Interventions on Preoperating Anxiety in Patients Undergoing Kidney Transplantation. Complement Med J faculty Nurs Midwifery. 2013;3(2):441-50.

18. Najafi S, Peyrovi H, Haghani H. . The effect of intraoperative progress report on anxiety of family members of patients under cardiac catheterization. Cardiovasc Nurs J. 2015;3(4):42-9.

19. Holland B, Pokorny ME. Slow stroke back massage: its effect on patients in a rehabilitation setting. Rehabil Nurs. 2001;26(5):182-6. [PubMed: 12035687].

20. Goodfellow LM. The effects of therapeutic back massage on psychophysiologic variables and immune function in spouses of patients with cancer. Nurs Res. 2003;52(5):318-28. [PubMed: 14501546].

21. Taylor AG, Galper DI, Taylor P, Rice LW, Andersen W, Irvin W, et al. Effects of adjunctive Swedish massage and vibration therapy on shortterm postoperative outcomes: a randomized, controlled trial.J Altern Complement Med. 2003;9(1):77-89. doi: 10.1089/107555303321222964. [PubMed:12676037].

22. Mokhtari Noori J, Sirati Nayer M, Sadeghi Shermeh M, Haji Amini Z, Javadinasab M. Effect of foot reflexology massage and Bensone relaxation on anxiety. J Behav Sci. 2009;3(2):159-65.

23. Torabi M, Salavati M, Sarabi AR. Effect of foot reflexology massage and Benson relaxation techniques on anxiety and physiological indexes of patients undergoing coronary heart angiography. Sci J Hamadan Nurs Midwifery Faculty. 2012;20(1):63-73.

24. Adib-Hajbaghery M, Rajabi-Beheshtabad R, Abasi A, Azizi-Fini E. The effect of massage therapy by a nurse and the patient's companion on the anxiety of male patients hospitalized in CCU: a clinical trial. Iran J Nurs. 2012;25(78):72-83.

25. Bauer BA, Cutshall SM, Wentworth LJ, Engen D, Messner PK, Wood $\mathrm{CM}$, et al. Effect of massage therapy on pain, anxiety, and tension after cardiac surgery: a randomized study. Complement Ther Clin Pract. 2010;16(2):70-5. doi: 10.1016/j.ctcp.2009.06.012. [PubMed: 20347836].

26. Billhult A, Bergbom I, Stener-Victorin E. Massage relieves nausea in women with breast cancer who are undergoing chemotherapy. $\mathrm{J} \mathrm{Al}$ tern Complement Med. 2007;13(1):53-7. doi: 10.1089/acm.2006.6049. [PubMed: 17309378]

27. Maryami Z, Modarres M, Taavoni S, Rahimi Foroushani A. Effect of Foot Massage on Pre-and Post Hysterectomy Anxiety.J Hayat. 2013;19(1):6575. 